\title{
The study of important agronomic traits by multivariate analysis in winter rapeseed cultivars
}

\author{
Gader Ghaffari ${ }^{1}$, Farhad Baghbani ${ }^{1}$, Behnam Tahmasebpour ${ }^{2}$ \\ ${ }^{1}$ Payame Noor University, East Azerbaijan Province, Islamic Republic of Iran \\ ${ }^{2}$ Department of Agronomy and plant breeding, faculty of Agricultural Engineering and Technology, Collage of Agriculture and Natural \\ resources, University of Tabriz, Tabriz, Iran
}

\section{Email address:}

tahmasbpor@yahoo.com (B. Tahmasebpour)

\section{To cite this article:}

Gader Ghaffari, Farhad Baghbani, Behnam Tahmasebpour. The Study of Important Agronomic Traits by Multivariate Analysis in Winter Rapeseed Cultivars. American Journal of Bioscience and Bioengineering. Vol. 2, No. 1, 2014, pp. 15-17.

doi: 10.11648/j.bio.20140201.13

\begin{abstract}
In order to group winter rapeseed cultivars according to evaluated traits, an experiment was conducted in the Research Greenhouse of Agriculture Faculty, University of Tabriz - IRAN. In the experiment were included 12 cultivars of winter rapeseed and 3 levels of water deficit stress. Gypsum blocks were used to monitor soil moisture. Water deficit stress was imposed from stem elongation to physiological maturity. According to the principal component analysis, five principal components were chosen with greater eigenvalue (more than 0.7 ) that are including $81.34 \%$ of the primeval variance of variables. The first component that explained the $48.02 \%$ of total variance had the high eigenvalue. The second component could justify about $13.64 \%$ of total variance and had positive association with leaf water potential and proline content and had negative relationship with leaf stomatal conductivity. The third, fourth and fifth components expressed around, 10.18, 4.83 and $4.68 \%$ of the total variance respectively. The third component had the high eigenvalue for plant dry weight. The fourth component put 1000-seed weight, seed yield, Silique per Plant and root dry weight against plant dry weight, chlorophyll fluorescence and leaf water potential. The fifth component had the high eigenvalue for root dry weight, root volume and 1000-seed weight.
\end{abstract}

Keywords: Winter Rapeseed, Water deficit Stress, Principal Component Analysis

\section{Introduction}

Rapeseed is the most important plant oil source and the third most important oil plant in the world after soybean (FAO, 2007). Typically the seed of new varieties contain $40 \%-45 \%$ Rapeseed oil which is used as raw materials to produce industrial and hydraulic oil, cleaner, soap and biodegradable plastics (Friedt, 2007). After extracting the oil, the remained oil cake, which contains $38-44 \%$ highquality proteins, is used for animal nutrition (Walker and Booth, 2001). Available water is one of the main limitations in the yield and quality for most species and it may appear during the whole growth stage or in critical conditions (Parry et al, 2005). Plants apply a range of particular responses in order to minimize the effects of water shortage or to increase water absorbing rate (Morison et al, 2008). The effect of water stress is a function of genotype, stress degree, weather condition, growth and developing stage of rapeseed (Robertson and Holland, 2004). Water stress in particular stages of rapeseed phenology affects seed qualitative properties such as oil and protein's percentage and the amount of glucosinolate (Strocher et al, 1995). Liang et al (1992) by evaluating the morphological and physiological responses to water stress showed that Brassica juncea is more adaptable to water stress than B.napus. The results of Kumar and Singh experiments (1998) indicate that in oily species of Brassica the genotypes with high osmotic adjustment maintained their cell turgid up to -2.4 Mega Pascal, but in genotypes with low osmotic adjustment, the fall rate in pressure potential was fast accordingly. Also Valeric et al (2002) remarked that when the separately planted rapeseed leaves were positioned under high osmotic laboratory, huge amount of proline flocked in leaves. Zulini et al (2002) found a significant correlation between Fv/Fm (Fv: variable chlorophyll fluorescence, Fm: maximum chlorophyll fluorescence) and leaf water potential in stressed plants so when leaf water potential decreases to less than 0.9 Mega 
Pascal, decrease in Fv/Fm can be observed. Numerous experiments suggest that the rapeseed yield is influenced by high number of pods per plant or per area unit (Rao and Mendham, 1991). Jensen et al (1996) reported that the eruption of water stress in vegetative growth and flowering stages didn't have significant effect on each rapeseed weight. However, during water shortage in seed filling stage their weight reduce. It has shown that supplemental irrigation of rapeseed increases the number of pods and seeds per pod by extending flowering stage (Kimber and McGregor, 1995).

\section{Materials and Methods}

The experiment was conducted under greenhouse conditions in Agricultural Faculty of Tabriz-Iran University, in 2007-2008. Temperature during the day was $23^{\circ} \mathrm{C}-25^{\circ} \mathrm{C}$ and during the night was between $15^{\circ} \mathrm{C}$ and $17^{\circ} \mathrm{C}$ with 14 hours lightening. The relative moist was between 50 and 60 percent.

\subsection{Plant Materials}

Plant material include 12 winter rapeseed cultivars named Zarfam, Okapi, Modena, Licord, Olera, Dexter, Arc4, Elite, Opera, SLM046, Fornax, and Orient kindly provided by Agricultural and Natural Resources Research Center of East Azerbaijan province-Iran. Cultivation was done in 8-kilogram (soil) flowerpots with 5 seeds planted in each. Then thinning was done when the plants had two leaves and one plant was kept in each flowerpot. Considering that cultivars were winter type, vernalization was done. Water deficit stress was imposed from stem elongation to physiological maturity. Gypsum blocks were used in order to control soil moist. The factorial experiment was done with two factors irrigation at 3 levels: well watered stress $(100 \%$ FC), mild stress $(75 \%$ FC), severe stress $(50 \%$ FC) and 12 winter rapeseed cultivars in randomized complete block design with 3 replications.

\subsection{Abbreviation}

LWP: Leaf Water Potential, RWC: Relative Water Content, LOP: Leaf Osmotic Potential, PC: Proline Content, CF: Chlorophyll Fluorescence, CI: Chlorophyll Index, LSC: Leaf Stomata Conductance, PH: Plant Height, PDW: Plant Dry Weight, RV: Root Volume, RDW: Root Dry Weight, SL: Silique Length, SPP: Silique per Plant, SPS: Seed Per Silique, 1000-SW: 1000-Seed Weight, SY: Seed Yield

\subsection{Measured Traits}

1 Leaf water potential measured by Pressure Chamber; model: Soil Moisture Equipment Crop, Sanata Barbara, CA.

2 Relative water content: The method of Morantmanceau et al (2004) was used. First the Fresh Weight (FW) of samples was measured. Then we put the samples in distilled water and after 24 hours the Turgid Wight (TW) was measured and after putting samples in $75^{\circ} \mathrm{C}$ Aven the Dry Weight (DW) was measured. Finally the leaf relative water content measured percent by this theorem:RWC= FW-DW/TW-DW*100

3 Osmotic potential measured by Osmometer; mode: Osmomat 010, Genotel.

4 Stomata conductance measured by Porometer; model: AP4- Porometer (Delta-T Devices) Cambridge, UK.

5 For chlorophyll fluorescence we used florometer; model: Opti Science, OS-30, USA.

6 Chlorophyll index is determined by Chlorophyll meter; model: SPAD-502, Minolta, Japan.

7 Proline contents were measured by Acid Hydrin method.

The plant height, plant dry weight, volume of root, root dry weight, length of silique, silique per plant, seed per silique and 1000-grain weight were measured at the end of growth stage.

In this study, the method of factor analysis was performed using SPSS software.

\section{Results and Discussion}

Principal component analysis grouped 12 cultivars based on traits that About $34 / 81 \%$ of the total variation, is explained by the first five principal components (Table 1). Selection based on principal component, the larger the number of eigen values of $\mathrm{A}$ and at least $80 \%$ of the total variance explained by the components, respectively. The first component is about $02 / 48 \%$ of the variation can be explained, with a high coefficient for the root volume (Table 2). The second component is about $64 / 13 \%$ of the original variables explained variation traits and leaf osmotic potential and proline content is positively associated with trait negative relationship between leaf stomatal conductivity (Table 2). The third component explained $18 / 10 \%$ of the total variation, with relatively high positive factor for plant dry weight (Table 2). The fourth component explains about $83 / 4$ percent of the variation equation is that the grain weight, grain yield per plant, number of pods per plant and root dry weight of the plant dry weight, chlorophyll fluorescence, and leaf water potential. The fifth component is about $68 / 4$ percent of the variation can be explained, with a high ratio of root dry weight, root volume and grain weight (Table 2).

Table 1. The results of component analysis.

\begin{tabular}{cccc}
\hline $\begin{array}{c}\text { Cumulative } \\
\text { percentage of } \\
\text { variance }\end{array}$ & Variance $\%$ & $\begin{array}{c}\text { Special } \\
\text { value }\end{array}$ & Component \\
\hline $48 / 02$ & $48 / 02$ & $7 / 68$ & 1 \\
$61 / 66$ & $13 / 64$ & $2 / 18$ & 2 \\
$71 / 83$ & $10 / 18$ & $1 / 63$ & 3 \\
$76 / 66$ & $4 / 83$ & $0 / 77$ & 4 \\
$81 / 34$ & $4 / 68$ & $0 / 75$ & 5 \\
\hline
\end{tabular}


Table 2. Subscribe coefficients of studied traits in component analysis.

\begin{tabular}{cccccc}
\hline $\mathbf{5}$ & $\mathbf{4}$ & $\mathbf{3}$ & $\mathbf{2}$ & $\mathbf{1}$ & \begin{tabular}{c} 
Trait \\
\cline { 5 - 5 }
\end{tabular} \\
\hline $0 / 096$ & $-0 / 366$ & $-0 / 045$ & $0 / 109$ & $0 / 104$ & LWP \\
$0 / 276$ & $-0 / 143$ & $-0 / 156$ & $0 / 125$ & $0 / 092$ & RWC \\
$-0 / 166$ & $0 / 080$ & $0 / 111$ & $0 / 375$ & $-0 / 033$ & LOP \\
$-0 / 091$ & $-0 / 046$ & $0 / 152$ & $0 / 361$ & $-0 / 042$ & PC \\
$0 / 307$ & $-0 / 286$ & $0 / 129$ & $0 / 077$ & $0 / 102$ & CF \\
$0 / 281$ & $-0 / 065$ & $0 / 095$ & $0 / 171$ & $0 / 096$ & CI \\
$0 / 028$ & $0 / 026$ & $-0 / 092$ & $-0 / 271$ & $0 / 076$ & LSC \\
$0 / 105$ & $-0 / 064$ & $0 / 059$ & $-0 / 081$ & $0 / 117$ & PH \\
$-0 / 031$ & $-0 / 298$ & $0 / 489$ & $-0 / 122$ & $0 / 044$ & PDW \\
$-0 / 506$ & $-0 / 154$ & $0 / 170$ & 0 & $0 / 94$ & RV \\
$-0 / 710$ & $0 / 333$ & $0 / 144$ & $-0 / 026$ & $0 / 090$ & RDW \\
$-0 / 029$ & $0 / 185$ & $-0 / 139$ & $-0 / 002$ & $0 / 110$ & SL \\
$0 / 019$ & $0 / 444$ & $-0 / 154$ & $0 / 138$ & $0 / 103$ & SPP \\
$0 / 055$ & $-0 / 059$ & $0 / 074$ & $-0 / 045$ & $0 / 113$ & SPS \\
$0 / 505$ & $0 / 596$ & $0 / 419$ & $-0 / 067$ & $-0 / 039$ & $1000-S W$ \\
$0 / 093$ & $0 / 477$ & $-0 / 040$ & $0 / 060$ & $0 / 114$ & SY \\
\hline
\end{tabular}

\section{References}

[1] FAO, 2007. http:// faostat. fao. org/.

[2] Friedt, W., Snowdon, R., Ordon, F., and Ahlemeyer, J. 2007. Plant Breeding: Assessment of genetic diversity in crop plants and is exploitation in breeding. Progress in Botany, 168: $152-177$.

[3] Germ, M. 2008. The response of two potato cultivars on combined effects of selenium and drought. Acta Agri. Slovenica, 91: 121-137.

[4] Jensen, C.R., Mogensen, V.O., Mortensen, G., Fieldsend, J.K., Milford, G.F.J., Anderson, M.N., and Thage, J. H. 1996. Seed glucosinolate, oil and protein content of fieldgrown rape (Brassica napus L.) affected by soil drying and evaporative demand. Field Crop Research, 47: 93-105.

[5] Jongdee, B., Fukai, S., and Cooper, M. 2002, Leaf water potential and osmotic adjustment as physiological traits to improve drought tolerance in rice. Field Crop Research, 76: 153-163.

[6] Kimber, D.S. and McGregor, D.I. 1995. The species and their origin, cultivation and world production. In: Kimber, D.S. and McCregorceds, D.I. (eds.). Brassica oilseed. CABI, PP: 1-7.

[7] Kumar, A. and Singh, D.P. 1998. Use of physiological indices as a screening technique for drought tolerance in oilseed Brassica species. Ann. Bot., 81: 413-420.

[8] Liang, Z.S., Diang Z.R., and Wang, S.T. 1992. Study on types of water stress adaptation in both Brassica napus $L$. and B. juncea L. Acta Botanica Boreali, Occidentalia Sinica., 12(1): 38-45.

[9] Mendham, N.J. and Salisbury, P.A. 1995. Physiolog: Crop development, growth and yield. In: Kimber, D. and McCregor. D.I. (eds). Brassica oilseed, CABI, Pp: 11-64.

[10] Morant-Manceau, A., Pradier, E., and Tremblin, G. 2004. Osmotic adjustment, gas exchanges and chlorophyll fluorescence of a hexaploid triticale and its parental species to salt stress. J. Plant Physiol., 169: 25-33.

[11] Morison, J.I., Baker, N.R., Mullineaux, P.M., and Davies, W.J. 2008. Improving water use in crop production. Philosophical Transactions of the Royal Society of London. Series B: Biological Sci., 363: 639-658.

[12] Mostajeran, A. and Rahimi- Eichi, V. 2009. Effect of drought stress on growth and yield of rice cultivars and accumulation of proline and soluble sugars in sheath and blades of their different age leaves. American- Eurasian J. Agri. and Envir. Sci., 5 (2): 264-272.

[13] Nasri, M., Zahedi, H., Tohidi Moghaddam, H.R., Ghooshchi F., and Paknejad, F. 2008. Investigation of water stress on macroelements in rapeseed genotypes leaf. American J. of Agri. and Biol., Sci., 3 (4): 669-672.

[14] Parry, M.A.J., Flexas, J., and Medrano, H. 2005. Prospects for crop production under drought: Research priorities and future directions. The Annals of Applied Biology, 147: 217226.

[15] Rao, M.S.S., and Mendham, N.J. 1991. Soil-plant-water relation of oilseed rape (Brassica napus and B. compestris). J. Agric Sci. Camb., 197: 197-205.

[16] Richard, R.A. 1996. Defining selection criteria to improve yield under drought. Plant Growth Regul., 20: 157-166.

[17] Robertson, M.J. and Holland, J.F. 2004. Production risk of canola in the semi-arid subtropics of Australia. Aust. J. Agric. Res., 55: 525-538.

[18] Sio-se Mardeh, A., Ahmadi, A., Poustini, K., and Mohammadi, V. 2006. Evaluation of drought resistance indices under various environmental conditions. Field Crop Res., 98: 222-229.

[19] Strocher, V.L., Boathe I.G., and Good, R.G. 1995. Molecular cloning and expression of a turgor gene in Brassica napus. Plant Mol Biol., 27: 541-551.

[20] Sundari, T., Tohari, S., and Mangoendidjojo, W. 2005. Yield performance and tolerance of mungbeam genotypes to shading. Ilmu. Pertanian, 12 (1): 12-19.

[21] Valeric, H.R., Sulpice, R., Lefort, C., Maerskack, V., Emery, N., and Larher, F.R. 2002. The suppression of osmoinduced proline response of Brassica napus $L$. var. Olefera leaf discs by polyunsatutated fatty acids and methyljasmonate. Plant Sci., 164: 119-127.

[22] Walker, K. C., and Booth, E. J. 2007, Agricultural aspcts of rape and other Brassica products. Eur J. Lipid Sci. Technol., 103: 441-446.

[23] Yucel, D.O., Anlarsal, A.E., and Yucel, C. 2006. Genetic variability, correlation and path analysis of yield and yield components in chickpea (Cicer arietinum L.). Turk. J. Agric., 30: $183-188$.

[24] Zulini, L., Rubinigg, M., Zorer, R., and Bertamini, M. 2002. Effects of drought stress on chlorophyll fluorescence and photosynthetic pigment in grapevine leaves (Vitis vinifera CV. White Riesling).www. Actahort. Org / html. 